\title{
Pitfalls in the Modeling of Forward-Looking Price Setting and Investment Decisions*
}

\author{
Tommy Sveen ${ }^{\dagger} \quad$ Lutz Weinke ${ }^{\ddagger}$
}

September 10, 2004

\begin{abstract}
The present paper makes progress in explaining the role of capital for inflation and output dynamics. We follow Woodford (2003, Ch. 5) in assuming Calvo pricing combined with a convex capital adjustment cost at the firm level. Our main result is that capital accumulation affects inflation dynamics primarily through its impact on the marginal cost. This mechanism is much simpler than the one implied by the analysis in Woodford's text. The reason is that his analysis suffers from a conceptual mistake, as we show. The latter obscures the economic mechanism through which capital affects inflation and output dynamics in the Calvo model, as discussed in Woodford (2004).
\end{abstract}

Keywords: Sticky Prices, Investments.

JEL Classification: E22, E31

*The authors are grateful to Jordi Galí. Thanks to seminar participants at the Annual Congress of the EEA, Central Bank Workshop on Macroeconomic Modelling, IX Workshop on Dynamic Macroeconomics, European University Institute, Norges Bank, and Universitat Pompeu Fabra. Special thanks to Farooq Akram, Larry Christiano, Christian Haefke, Omar Licandro, Albert Marcet, Martin Menner, Ricardo Reis, Philip Sauré, Stephanie Schmitt-Grohé, Mike Woodford, and Fredrik Wulfsberg. The usual disclaimer applies. The views expressed in this paper are those of the authors and should not be attributed to Norges Bank.

${ }^{\dagger}$ Research Department, Norges Bank (The Central Bank of Norway), e-mail: tommy.sveen@norges-bank.no

$\ddagger$ Universitat Pompeu Fabra, e-mail: lutz.weinke@upf.edu 


\section{Introduction}

By now there exists a large literature studying business cycles using dynamic NewKeynesian (DNK) models, i.e. stochastic general equilibrium models with imperfect competition and nominal rigidities. ${ }^{1}$ However, it is generally assumed that labor is the only productive input, or alternatively, that the capital stock in the economy is constant. ${ }^{2}$ Woodford (2003, p. 352) comments on these modeling choices: '[...] while this has kept the analysis of the effects of interest rates on aggregate demand quite simple, one may doubt the accuracy of the conclusions obtained, given the obvious importance of variations in investment spending both in business fluctuations generally and in the transmission mechanism for monetary policy in particular.'

DNK models that introduce capital accumulation typically assume a rental market. ${ }^{3}$ In the present paper we follow Woodford (2003, Ch. 5) in assuming staggered price setting à la Calvo combined with firm-specific capital in the following sense: we assume a convex capital adjustment cost at the firm level. ${ }^{4}$ Along the way we show that the analysis in Woodford's text suffers from a conceptual mistake. ${ }^{5}$ In a nutshell: he does not assess correctly over what set of future states of the world an optimizing Calvo price setter forms expectations. ${ }^{6}$

Our ultimate goal is to assess the role of endogenous firm-specific capital for inflation and output dynamics. To this end we analyze impulse responses to a shock in the exogenous growth rate of money balances for two cases: ${ }^{7}$ our baseline model

\footnotetext{
${ }^{1}$ See, e.g., Clarida et al. (1999) and Chari et al. (2000).

${ }^{2}$ Erceg et al. (2000) assume a constant aggregate capital stock combined with a rental market for capital, while Sbordone (2002) and Galí et al. (2001) assume constant capital at the firm level.

${ }^{3}$ See, e.g., Yun (1996), Smets and Wouters (2003), Christiano et al. (2004), and Schmitt-Grohé and Uribe (2004). However, Sveen and Weinke (2004a,b) show that the rental market assumption is not innocuous in a model with staggered price setting.

${ }^{4}$ Since we wrote and circulated the first version of the present paper there have been other contributions studying firm-specific capital in a Calvo-style model. See, e.g., Altig et al. (2004), Eichenbaum and Fisher (2004), and Woodford (2004).

${ }^{5}$ The mistake has been originally noted in Sveen and Weinke (2003).

${ }^{6}$ The same critique applies to Casares (2002).

${ }^{7}$ In an earlier version of the present paper (Norges Bank Working paper 1/2004, http: \\www.norges-bank.no) we solve the model using an iterative procedure. In the present version we follow Woodford (2004) and use the method of undetermined coefficients.
} 
with endogenous capital (henceforth baseline) and a specification with decreasing returns to scale resulting from a constant capital stock at the firm level (henceforth DRS). We find the following: first, the response of output is larger in the baseline model - both on impact and during the transition period. Second, the inflation dynamics are similar in the two models.

The intuition is surprisingly simple: first, endogenous capital at the firm level affects inflation dynamics primarily through its impact on the marginal cost. The inflation equation, however, changes only to a negligible extent with respect to the one derived by Sbordone (2002) and Galí et al. (2001) under the assumption that the capital stock is constant at the firm level. Second, there are two opposite effects from capital accumulation on the determination of the marginal cost. On the one hand, the additional production triggered by investment demand increases the marginal cost in the baseline model with respect to the DRS specification. On the other hand, the resulting additional capital increases the economy's productive capacity, thereby decreasing the marginal cost. The latter is anticipated by forward-looking price setters. This explains why the two models display similar inflation dynamics even though the output response is consistently larger with endogenous firm-specific capital.

This mechanism is indeed much simpler than the one outlined in Woodford (2003, Ch. 5). His analysis implies that firm-specific capital combined with Calvo pricing results in a substantial change in the dynamic relationship between marginal cost and inflation. This obscures the economic mechanism through which capital affects inflation and output dynamics, as discussed in Woodford (2004). ${ }^{8}$

The remainder of the paper is organized as follows: Section 2 outlines the baseline model. In particular, it is shown why the price setting problem associated with that structure has not been solved in a correct way in Woodford (2003, Ch. 5). In Section 3 we present and interpret our results. Section 4 concludes.

\footnotetext{
${ }^{8}$ One particularly problematic feature of the inflation equation in Woodford (2003, Ch. 5) is that an increase in expected future marginal cost may result in a decrease in current inflation. Thanks to Larry Christiano for drawing our attention to this point.
} 


\section{The Model}

We follow the general equilibrium structure outlined in Woodford (2003, Ch. 5). ${ }^{9}$ There are two sectors, households and firms. Households choose labor supply and consumption demand. They have access to complete financial markets and supply labor in a perfectly competitive market. Firms produce differentiated goods and act under monopolistic competition. They face restrictions on both price adjustment and capital accumulation.

The only aggregate uncertainty comes from the growth rate of money balances, which we assume to follow an $A R(1)$ process:

$$
\Delta m_{t}=\rho_{m} \Delta m_{t-1}+\varepsilon_{t}
$$

where $\Delta$ denotes the difference operator, and $m_{t}$ is the log of nominal money balances $M_{t}$ at time $t$. The autoregressive parameter, $\rho_{m}$, is assumed to be strictly positive and less than one. Finally, $\varepsilon_{t}$ is assumed to be iid with zero mean and variance $\sigma_{\varepsilon}^{2}$.

\subsection{Households}

A representative household maximizes expected discounted utility:

$$
E_{t} \sum_{k=0}^{\infty} \beta^{k} U\left(C_{t+k}, N_{t+k}\right)
$$

where $E_{t}$ denotes the expectational operator conditional on information available up to time $t$. Furthermore, $U(\cdot)$ is period utility, and parameter $\beta$ is the discount factor. Hours worked in period $t$ are denoted $N_{t}$. Finally, $C_{t} \equiv\left(\int_{0}^{1} C_{t}(i)^{\frac{\varepsilon-1}{\varepsilon}} d i\right)^{\frac{\varepsilon}{\varepsilon-1}}$ denotes the time $t$ Dixit-Stiglitz consumption aggregator, and parameter $\varepsilon$ is the elasticity of substitution between different varieties of goods $C_{t}(i)$.

\footnotetext{
${ }^{9}$ His model is more general than ours. However, this is irrelevant for our dicussion of the conceptual mistake in his treatment of optimal price-setting with endogenous capital.
} 
The maximization is subject to a sequence of budget constraints:

$$
\int_{0}^{1} P_{t}(i) C_{t}(i) d i+E_{t}\left\{Q_{t, t+1} D_{t+1}\right\} \leq D_{t}+W_{t} N_{t}+T_{t}
$$

where $Q_{t, t+1}$ and $D_{t+1}$ denote, respectively, the stochastic discount factor for random nominal payments and the nominal payoff associated with the portfolio held at the end of period $t$. Moreover, $P_{t}(i)$ gives the nominal price of variety $i$ at time $t, W_{t}$ is the nominal wage as of that period, and $T_{t}$ denotes profits resulting from ownership of firms.

We assume a standard period utility:

$$
U\left(C_{t}, N_{t}\right)=\frac{C_{t}^{1-\sigma}}{1-\sigma}-\frac{N_{t}^{1+\phi}}{1+\phi}
$$

where parameter $\sigma$ denotes household's relative risk aversion, and parameter $\phi$ can be interpreted as the the inverse of the aggregate Frisch labor supply elasticity.

Cost minimization by households implies that for each variety of goods the consumption demand function reads:

$$
C_{t}^{d}(i)=\left(\frac{P_{t}(i)}{P_{t}}\right)^{-\varepsilon} C_{t},
$$

where $P_{t} \equiv\left(\int_{0}^{1} P_{t}(i)^{1-\varepsilon} d i\right)^{\frac{1}{1-\varepsilon}}$ denotes the price index. The latter has the property that the minimum expenditure required to purchase a bundle of goods resulting in $C_{t}$ units of the composite good is given by $P_{t} C_{t}$.

The remaining first order conditions associated with the household's problem are as follows:

$$
\begin{aligned}
C_{t}^{\sigma} N_{t}^{\phi} & =\frac{W_{t}}{P_{t}} \\
\beta\left(\frac{C_{t+1}}{C_{t}}\right)^{-\sigma}\left(\frac{P_{t}}{P_{t+1}}\right) & =Q_{t, t+1} .
\end{aligned}
$$


The first equation is the optimality condition for labor supply, and the second is a standard intertemporal optimality condition. Finally, let us note that the price of a risk-less one-period bond is given by $R_{t}^{-1}=E_{t} Q_{t, t+1}$, where $R_{t}$ denotes the gross nominal interest rate.

\subsection{Firms}

Firms are indexed on the unit interval. Each firm has access to a Cobb-Douglas production technology:

$$
Y_{t}(i)=K_{t}(i)^{\alpha} N_{t}(i)^{1-\alpha}
$$

where $K_{t}(i)$ and $N_{t}(i)$ denote, respectively, capital holdings and labor input used by firm $i$ in its period $t$ production denoted $Y_{t}(i)$. Parameter $\alpha$ is the capital share.

Each firm $i$ makes an investment decision at any point in time with the resulting additional capital becoming productive one period after the investment decision is made. As in Woodford (2003, Ch. 5) we assume the following: first, the investment good is a Dixit-Stiglitz aggregate of all of the goods in the economy with the same constant elasticity of substitution as in the consumption aggregate. Second, firms face a convex adjustment cost of changing their capital holdings. Given firm $i$ 's time $t$ capital stock $K_{t}(i)$ the amount of the composite good $I_{t}(i)$ that has to be purchased by that firm at this point in time in order to have a capital stock $K_{t+1}(i)$ in place in the next period is given by:

$$
I_{t}(i)=I\left(\frac{K_{t+1}(i)}{K_{t}(i)}\right) K_{t}(i)
$$

Function $I(\cdot)$ has the following characteristics: $I(1)=\delta, I^{\prime}(1)=1$, and $I^{\prime \prime}(1)=$ $\epsilon_{\psi}$. Parameter $\delta$ denotes the depreciation rate. Eichenbaum and Fisher (2004) interpret parameter $\epsilon_{\psi}$ as the elasticity of the investment to capital ratio with respect to Tobin's q, evaluated in steady state. Parameter $\epsilon_{\psi}$ is assumed to be strictly larger than zero and it measures the convex capital adjustment cost in a log-linear 
approximation to the equilibrium dynamics.

Firms post sticky prices à la Calvo (1983), i.e. each period a measure $(1-\theta)$ is randomly selected. Those firms change their prices and the remaining firms post their last period's nominal prices. Cost minimization by firms and households implies that demand for each individual good $i$ in period $t$ can be written as follows:

$$
Y_{t}^{d}(i)=\left(\frac{P_{t}(i)}{P_{t}}\right)^{-\varepsilon} Y_{t}^{d}
$$

where $Y_{t}^{d} \equiv C_{t}+I_{t}$ denotes aggregate time $t$ demand, and $I_{t} \equiv \int_{0}^{1} I_{t}(i) d i$ is aggregate time $t$ investment demand.

With probability $\theta^{k}$ a price that was chosen at time $t$ will still be posted at time $t+k$. When setting a new price $P_{t}^{*}(i)$ in period $t$ firm $i$ maximizes the current value of its dividend stream over the expected lifetime of the chosen price. Formally, given $K_{t}(i)$ a time $t$ price setter chooses contingent plans for $\left\{P_{t+k}^{*}(i), K_{t+k+1}(i), N_{t+k}(i)\right\}_{k=0}^{\infty}$ in order to solve the following problem: ${ }^{10}$

$$
\max \sum_{k=0}^{\infty} E_{t}\left\{Q_{t, t+k}\left[Y_{t+k}^{d}(i) P_{t+k}(i)-W_{t+k} N_{t+k}(i)-P_{t+k} I_{t+k}(i)\right]\right\}
$$

s.t.

$$
\begin{aligned}
Y_{t+k}^{d}(i) & =\left(\frac{P_{t+k}(i)}{P_{t+k}}\right)^{-\varepsilon} Y_{t+k}^{d}, \\
Y_{t+k}^{d}(i) & \leq N_{t+k}(i)^{1-\alpha} K_{t+k}(i)^{\alpha}, \\
I_{t+k}(i) & =I\left(\frac{K_{t+k+1}(i)}{K_{t+k}(i)}\right) K_{t+k}(i), \\
P_{t+k+1}(i) & = \begin{cases}P_{t+k+1}^{*}(i) & \text { with prob. }(1-\theta) \\
P_{t+k}(i) & \text { with prob. } \theta\end{cases}
\end{aligned}
$$

\footnotetext{
${ }^{10} \mathrm{~A}$ firm $j$ that is restricted to change its price at time $t$ solves the same problem, except for the fact that it takes $P_{t}(j)$ as given.
} 
The implied first order condition for capital accumulation reads:

$$
\frac{d I_{t}(i)}{d K_{t+1}(i)} P_{t}=E_{t}\left\{Q_{t, t+1}\left[M S_{t+1}(i)-\frac{d I_{t+1}(i)}{d K_{t+1}(i)} P_{t+1}\right]\right\}
$$

where $M S_{t+1}(i)$ denotes the nominal marginal savings in firm $i$ 's labor cost associated with having one additional unit of capital in place in period $t+1$. The intuition behind the last equation is the following: the marginal cost of installing an additional unit of capital at time $t$ (including the adjustment cost) is equalized to the expected discounted marginal contribution to the firm's value associated with having that additional unit of capital in place at point in time $t+1$. The latter is given by the marginal return from using it for production, $M S_{t+1}(i)$, and selling the remaining capital after depreciation (net of the change in the time $t+1$ adjustment cost that is associated with the time $t$ investment decision). As has been emphasized by Woodford (2003, Ch. 5), the relevant measure of the marginal return to capital is the marginal savings in a firm's labor cost: firms are demand constrained and hence the return from having an additional unit of capital in place results from the fact that this allows to produce the quantity that happens to be demanded using less labor.

The following relationship holds true:

$$
M S_{t}(i)=W_{t} \frac{M P K_{t}(i)}{M P L_{t}(i)}
$$

where $M P K_{t}(i)$ and $M P L_{t}(i)$ denote, respectively, the marginal product of capital and labor of firm $i$ in period $t$.

The first order condition for price setting is given by:

$$
\sum_{k=0}^{\infty} \theta^{k} E_{t}\left\{Q_{t, t+k} Y_{t+k}^{d}(i)\left[P_{t}^{*}(i)-\mu M C_{t+k}(i)\right]\right\}=0,
$$

where $\mu \equiv \frac{\varepsilon}{\varepsilon-1}$ is the frictionless mark-up over marginal costs, and $M C_{t}(i)$ denotes 
the nominal marginal cost of firm $i$ in period $t$. The latter is given by:

$$
M C_{t}(i)=\frac{W_{t}}{M P L_{t}(i)}
$$

Equation (14) is the familiar first order condition implied by the Calvo model: optimizing price setters behave in a forward-looking manner, i.e. they take into account not only current but also future expected marginal costs in those states of the world where the chosen price is still posted. ${ }^{11}$ The only non-standard feature in equation (14) is that capital affects labor productivity and hence a firm's marginal cost. This aspect of a firm's price setting decision results in an intricate problem. As we argue next, the latter has not been solved in a correct way in Woodford (2003, Ch. 5).

\subsection{A Short Note on Woodford's Conceptual Mistake}

To fix ideas we represent firm $i$ 's price setting problem at time $t$ by a simple tree, which consists of the states of the world that are consistent with the current state $S$. This is shown in Figure 1. Equations (14) and (15) prescribe that the relevant capital holdings are associated with those states of the world where the newly set price is still posted. We refer to these states as the Calvo states. In Figure 1 they are assumed to correspond to nodes $S, S 0, S 00, \ldots$ in the tree. Firm $i$ 's capital stock at node $S$ is predetermined.

\section{[Figure 1 about here]}

The conceptual mistake in Woodford (2003, pp. 688 - 690) is that he computes firm $i$ 's time $t$ expectation of its future capital holdings in the Calvo states without acknowledging that this expectation depends on that firm's time $t$ expectation regarding its future optimally chosen prices. Specifically, he restricts attention to firm

\footnotetext{
${ }^{11}$ We follow a large literature on the Calvo model in using the notation $E_{t}$ in equation (14) to indicate an expectation that is conditional on the time $t$ state of the world, but integrating only over those future states in which firm $i$ has not reset its price since period $t$. Woodford (2004) uses $\widehat{E}_{t}^{i}$ in order to denote this expectation.
} 
$i$ 's time $t$ expectation of its future relative prices in the Calvo states. This is not correct, as we show next.

Clearly, it is enough to show that firm $i$ 's time $t$ expectation regarding one of its future capital holdings in the Calvo states is computed in an incorrect way. To this end we consider firm $i$ 's time $t$ choice of its next period's capital stock. Equations (12) and (13) state that this choice takes rationally into account that firm $i$ 's time $t+1$ price might be optimally chosen. But this means that the possibility of choosing a new price in period $t+1$ affects a price setter's time $t$ investment decision and hence its time $t+1$ capital stock, in particular, if node $\mathrm{S} 0$ is reached at point in time $t+1$. Therefore, firm $i$ 's time $t$ expectation regarding its capital holdings in the Calvo states does depend on its time $t$ expectation regarding future optimally chosen prices, as we have claimed.

\subsection{Market Clearing}

Clearing of the labor market requires that hours worked, $N_{t}$, are given by the following equation, which holds for all $t$ :

$$
N_{t}=\int_{0}^{1} N_{t}(i) d i
$$

Moreover, it is useful to define time $t$ aggregate capital $K_{t} \equiv \int_{0}^{1} K_{t}(i) d i$ and auxiliary variable $Y_{t} \equiv K_{t}^{\alpha} N_{t}^{1-\alpha} \cdot{ }^{12}$

For each variety $i$ supply, $Y_{t}(i)$, must equal demand:

$$
Y_{t}(i)=C_{t}^{d}(i)+I_{t}^{d}(i)
$$

where $I_{t}^{d}(i)$ denotes investment demand for good $i$.

\footnotetext{
${ }^{12}$ The difference between $Y_{t}$ and aggregate output in the economy is of the second order.
} 


\subsection{Linearized Equilibrium Conditions}

We restrict attention to a log-linear approximation to the equilibrium dynamics around a steady state with zero inflation. In what follows, the percent deviation of a variable with respect to its steady state value is denoted by a hat.

\subsubsection{Households}

Log-linearizing and rearranging the first order condition (7) we obtain the household's Euler equation:

$$
\widehat{C}_{t}=E_{t} \widehat{C}_{t+1}-\frac{1}{\sigma}\left(i_{t}-E_{t} \pi_{t+1}-\rho\right)
$$

where $i_{t}$ denotes the time $t$ nominal interest rate, and $\pi_{t} \equiv \log \left(\frac{P_{t}}{P_{t-1}}\right)$ is the rate of inflation. Finally, the time discount rate is given by $\rho \equiv-\log \beta$.

Log-linearizing the household's labor supply equation (6) results in:

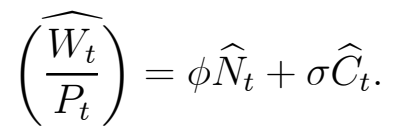

For convenience, we follow Galí (2000) and assume a standard demand for real balances $\frac{M_{t}}{P_{t}}$ :

$$
\widehat{\left(\frac{M_{t}}{P_{t}}\right)}=\widehat{Y}_{t}-\eta\left(i_{t}-\rho\right),
$$

where parameter $\eta$ denotes the semi-elastisity of demand for real balances with respect to the nominal interest rate.

\subsubsection{Firms}

Law of Motion of Capital We log-linearize the first order condition for investment (12) and average over all firms in the economy. ${ }^{13}$ Combining the resulting relationship with the Euler equation (18) we obtain the following law of motion of

\footnotetext{
${ }^{13}$ For details see Woodford (2003, Ch. 5).
} 
the aggregate capital stock:

$$
\begin{aligned}
\widehat{K}_{t+1}= & \frac{1}{1+\beta} \widehat{K}_{t}+\frac{\beta}{(1+\beta)} E_{t} \widehat{K}_{t+2} \\
& +\frac{1-\beta(1-\delta)}{\epsilon_{\psi}(1+\beta)} E_{t} \widehat{m s}_{t+1}-\frac{1}{\epsilon_{\psi}(1+\beta)}\left(i_{t}-E_{t} \pi_{t+1}-\rho\right),
\end{aligned}
$$

where $m s_{t} \equiv \int_{0}^{1} \frac{M S_{t}(i)}{P_{t}} d i$ denotes the average real marginal savings in labor costs at time $t$.

Inflation Dynamics The inflation equation is derived from averaging optimal price setting decisions and aggregating prices via the price index. A natural starting point is the log-linearized real marginal cost at the firm level. The latter reads:

$$
\widehat{m c}_{t}(i)=\widehat{m c}_{t}-\frac{\varepsilon \alpha}{1-\alpha} \widehat{p}_{t}(i)-\frac{\alpha}{1-\alpha} \widehat{k}_{t}(i)
$$

where $k_{t}(i) \equiv \frac{K_{t}(i)}{K_{t}}$ and $m c_{t} \equiv \int_{0}^{1} \frac{M C_{t}(i)}{P_{t}} d i$ denotes the average time $t$ real marginal cost in the economy.

We refer to $\widehat{k}_{t}(i)$ as firm $i$ 's capital gap at time $t$. The intuition behind equation (22) is the following: for a zero capital gap a firm that posts a higher than average price faces a lower than average marginal cost due to the decreasing marginal product of labor. This is reflected in the second term, and it is exactly as in Sbordone (2002) and Galí et al. (2001) for models with decreasing returns to scale and labor as the only variable input in production. With capital accumulation there is an extra effect coming from the firm's capital stock, which corresponds to the last term. Conditional on posting the average price in the economy a firm that has a higher than average capital stock in place faces a lower than average marginal cost. The reason is that the marginal product of labor increases with the capital stock used by the firm.

Invoking equations (14) and (22) the optimal relative price of firm $i$ at time $t$, 
$p_{t}^{*}(i) \equiv \frac{P_{t}^{*}(i)}{P_{t}}$, can be log-linearized as:

$$
\widehat{p}_{t}^{*}(i)=\sum_{k=1}^{\infty}(\beta \theta)^{k} E_{t} \pi_{t+k}+\xi \sum_{k=0}^{\infty}(\beta \theta)^{k} E_{t} \widehat{m c}_{t+k}-\psi \sum_{k=0}^{\infty}(\beta \theta)^{k} E_{t} \widehat{k}_{t+k}(i),
$$

where $\xi \equiv \frac{(1-\beta \theta)(1-\alpha)}{1-\alpha+\varepsilon \alpha}$, and $\psi \equiv \frac{(1-\beta \theta) \alpha}{1-\alpha+\varepsilon \alpha} \cdot{ }^{14}$ Hence, in addition to the usual inflation and average marginal cost terms a firm's optimal price setting decision does also depend on its current and future expected capital gaps over the (random) lifetime of the chosen price.

Woodford (2004) shows that the associated inflation equation takes the following simple form:

$$
\pi_{t}=\beta E_{t} \pi_{t+1}+\kappa \widehat{m c}_{t},
$$

where $\kappa$ is a parameter which he computes numerically. ${ }^{15}$

Finally, we note that the following aggregate production function holds, up to a first-order approximation:

$$
\widehat{Y}_{t}=\alpha \widehat{K}_{t}+(1-\alpha) \widehat{N}_{t}
$$

\subsubsection{Market clearing}

Since equation (17) holds for each variety in the economy we are entitled to integrate on both sides over all of them. After invoking (8), (9), and (10), we log-linearize the resulting relationship and obtain:

$$
\widehat{Y}_{t}=\zeta \widehat{C}_{t}+(1-\zeta) \frac{1}{\delta}\left[\widehat{K}_{t+1}-(1-\delta) \widehat{K}_{t}\right]
$$

where $\zeta \equiv \frac{\rho+\delta(1-\alpha)}{\rho+\delta}$ denotes the steady state consumption to output ratio. The steady state capital to output ratio is given by $(1-\zeta) \frac{1}{\delta}$.

\footnotetext{
${ }^{14}$ The price setting problem is stated in terms of variables that are constant in the steady state.

${ }^{15}$ See the Appendix for an outline of the Woodford (2004) solution.
} 


\section{Equilibrium Dynamics}

Given the specification of monetary policy in (1), the equilibrium processes for the nominal interest rate, output, hours, consumption, real wage, real balances, capital, and inflation are given by equations (26), (25), (18), (19), (20), (21), and (24). ${ }^{16}$ We analyze impulse responses to a positive one standard deviation shock in the growth rate of money balances.

\subsection{Calibration}

The period length is one quarter. We choose $\epsilon_{\psi}=3$, as suggested by Woodford (2003, Ch. 5) and the references herein. The intertemporal elasticity of substitution is given by $\frac{1}{\sigma}$. Assuming $\sigma=2$ is in line with empirical estimates. ${ }^{17}$ Consistent with a unit labor supply elasticity, we assume $\phi=1$. The semi-elasticity of demand for real balances with respect to the nominal interest rate, $\eta$, is set to unity implying an empirically plausible value of about 0.05 for the interest rate elasticity. The capital share in the production function, $\alpha$, is 0.36 . We set $\beta=0.99$ implying an average annual real return of about 4 percent. Setting $\theta=0.75$ means that the average lifetime of a price is equal to one year. Consistent with the estimated autoregressive process for M1 in the United States we assume $\rho_{m}=0.5$ and $\sigma_{\varepsilon}^{2}=0.1{ }^{18}$ Setting $\varepsilon=11$ implies a frictionless markup of 10 percent. $^{19}$

\subsection{Results}

We compare the responses to a monetary policy shock for the baseline model and a specification with decreasing returns to scale resulting from a constant capital stock at the firm level. The result is shown is Figure 2: first, output is higher in the former

\footnotetext{
${ }^{16}$ To solve the dynamic stochastic system of equations we use Dynare (http://www.cepremap.cnrs.fr/dynare/). Thanks to Larry Christiano for providing us with Matlab code, which we have used in computing $\kappa$.

${ }^{17}$ See, e.g., Basu and Kimball (2003) and the references herein.

${ }^{18}$ Our calibration of $\phi, \alpha, \beta, \theta, \rho_{m}$, and $\sigma_{\varepsilon}^{2}$ is justified in Galí (2000) and the references herein.

${ }^{19}$ This is consistent with the estimate in Galí et al. (2001).
} 
- both on impact and during the transition period. Second, the inflation dynamics are similar in the two models.

\section{[Figure 2 about here]}

Let us develop the intuition behind our result. We start by observing that firm-specific capital affects inflation dynamics primarily through its impact on the marginal cost. The form of the inflation equation, however, is only affected to some negligible extent by the feature of capital accumulation at the firm level: if $\kappa$ in equation (24) is approximated by the coefficient premultiplying the marginal cost in the inflation equation associated with the DRS specification, ${ }^{20}$ then the resulting loss in accuracy is negligible, as shown in Figure $3 .^{21}$ The reason is as follows. To the extent that there exists a capital adjustment cost the firm's investment decision is forward-looking. If the planning horizon for the investment decision is long enough, then price setters and non-price setters do not make very different investment decisions, on average. The fact that they face the same probabilities of being allowed or restricted to change their prices over the relevant planning horizon leads to a small difference in their current investment decisions and, more generally, in their expected investment policies.

\section{[Figure 3 about here]}

Next we note that there are two counteracting effects from capital accumulation on the determination of the marginal cost. On the one hand, investment spending adds to aggregate demand, thereby implying higher production and an increase in the marginal cost in response to the shock. On the other hand, the additional capital resulting from investment spending in one period increases the economy's productive capacity in subsequent periods. This implies a decrease in marginal costs.

\footnotetext{
${ }^{20}$ Sbordone (2002) and Galí et al. (2001) show that this coefficient takes the following form: $\frac{(1-\beta \theta)(1-\theta)}{\theta} \frac{1-\alpha}{1+\alpha(\varepsilon-1)}$.

${ }^{21}$ We acknowledge a tiny difference between the baseline impulse responses reported in the earlier version of the paper and the ones shown in Figures 2 and 3. In order to put this in perspective we note, however, that for each variable the maximum difference is more than eight times smaller than the corresponding maximum difference in Figure 3. The reason for why we formerly did not choose an even higher accuracy lies in the lack of computational efficiency of the iterative procedure that we used to solve the model.
} 
The intuition behind the results shown in Figure 2 is therefore surprisingly simple. First, firm-specific capital affects inflation dynamics primarily through its impact on the marginal cost. Second, there are two counteracting effects from endogenous capital accumulation on the determination of the marginal cost. The latter is anticipated by forward-looking price setters. This explains why the baseline model and the DRS specification display similar inflation dynamics even though the output response is consistently larger in the former.

\section{Conclusion}

The present paper makes progress in explaing the economic mechanism through which capital accumulation affects inflation and output dynamics. We use a Calvostyle model with a convex capital adjustment cost at the firm level. Our main finding is that firm-specific capital accumulation affects primarily the determination of the marginal cost. The form of the inflation equation, however, changes only to a negligible extent compared with a model where the capital stock at the firm level is assumed to be constant. Combined with the fact that investment demand has counteracting effects on the determination of the marginal cost this leads to a surprisingly simple intuition for the associated inflation and output dynamics. This economic mechanism has been obscured by a conceptual mistake in Woodford (2003, Ch. 5), as we show.

In related work Sveen and Weinke (2004a,b) find that the convenient and widely used alternative modelling choice of assuming a rental market for capital is not innocuous. This highlights the importance of the insights developed in the present paper. 


\section{Appendix: Inflation Dynamics}

Woodford (2004) posits that the price chosen by a Calvo price setter $i$ is:

$$
\widehat{p}_{t}^{*}(i)=\widehat{p}_{t}^{*}-\tau_{1} \widehat{k}_{t}(i)
$$

where $\tau_{1}$ is an unknown parameter. He further assumes that the investment decision of any firm $j$ satisfies:

$$
\widehat{k}_{t+1}(j)=\tau_{2} \widehat{k}_{t}(j)+\tau_{3} \widehat{p}_{t}(j)
$$

where $\tau_{2}$ and $\tau_{3}$ are two additional unknown parameters.

Finally, he invokes the relationship between the log-linearized average newly set price, $\widehat{p}_{t}^{*}$, and inflation, $\pi_{t}$ :

$$
\pi_{t}=\frac{1-\theta}{\theta} \widehat{p}_{t}^{*}
$$

Combined with the first-order conditions for price setting and investment it is possible to pin down the unknown coefficients $\tau_{1}, \tau_{2}$, and $\tau_{3}$ and to derive the inflation equation (24), along the lines outlined in Woodford (2004). 


\section{References}

Altig, David, Lawrence J. Christiano, Martin Eichenbaum, and Jesper Linde (2004):

"Firm-Specific Capital, Nominal Rigidities, and the Business Cycle", mimeo.

Basu, Susanto, and Miles S. Kimball (2003): "Investment Planning Costs and the Effects of Fiscal and Monetary Policy", mimeo.

Calvo, Guillermo (1983): "Staggered Prices in a Utility Maximizing Framework", Journal of Monetary Economics, 12(3), 383-398.

Casares, Miguel (2002), "Time-to-Build Approach in a Sticky Price, Sticky Wage Optimizing Monetary Model", European Central Bank Working Paper No. 147.

Chari, V. V., Patrick J. Kehoe, and Ellen R. McGratten (2000): "Sticky Price Models of the Business Cycle: Can the Contract Multiplier Solve the Persistence Problem", Econometrica, 68, 1151-1179.

Christiano, Lawrence J., Martin Eichenbaum, and Charles Evans (2004): "Nominal Rigidities and the Dynamic Effects of a Shock to Monetary Policy", forthcoming in Journal of Political Economy.

Clarida, Richard, Jordi Galí, and Mark Gertler (1999): "The Science of Monetary Policy: a New Keynesian Perspective", Journal of Economic Literature, 37(4), 16611707.

Eichenbaum, Martin and Jonas D. M. Fisher (2004): "Evaluating the Calvo Model of Sticky Prices", NBER Working Paper 10617.

Erceg, Christopher J., Dale W. Henderson, and Andrew T. Levin (2000): "Optimal Monetary Policy with Staggered Wage and Price Contracts", Journal of Monetary Economics, 46(2), 281-313.

Galí, Jordi (2000): "New Perspectives on Monetary Policy, Inflation, and the Business Cycle", mimeo. 
Galí, Jordi, Mark Gertler, and David López-Salido (2001): "European Inflation Dynamics", European Economic Review, 45(7), 1237-1270.

Sbordone, Argia M. (2002): "Prices and Unit Labor Costs: A New Test of Price Stickiness", Journal of Monetary Economics, 49, 265-292.

Smets, F. and R. Wouters (2003): "An Estimated Stochastic Dynamic General Equilibrium Model of the Euro Area", Journal of the European Economic Association, $1,1123-1175$.

Schmitt-Grohé, Stephanie, and Martin Uribe (2004): "Optimal Simple and Implementable Monetary and Fiscal Rules", NBER Working Paper 10253.

Sveen, Tommy, and Lutz Weinke (2003): "Inflation and Output Dynamics with Firm-owned Capital", Universitat Pompeu Fabra Working Paper No. 702.

Sveen, Tommy, and Lutz Weinke (2004): "New Perspectives on Capital and Sticky Prices", Norges Bank Working Paper 2004/3.

Sveen, Tommy, and Lutz Weinke (2004): "Firm-Specific Investment, Sticky Prices, and the Taylor Principle", Universitat Pompeu Fabra, mimeo.

Woodford, Michael (2003): Interest and Prices: Foundations of a Theory of Monetary Policy, Princeton University Press.

Woodford, Michael (2004): "Inflation and Output Dynamics with Firm-Specific Investment", Princeton University, mimeo.

Yun, Tack (1996), "Nominal Price Rigidity, Money Supply Endogeneity, and Business Cycles", Journal of Monetary Economics, 37, 345-370. 


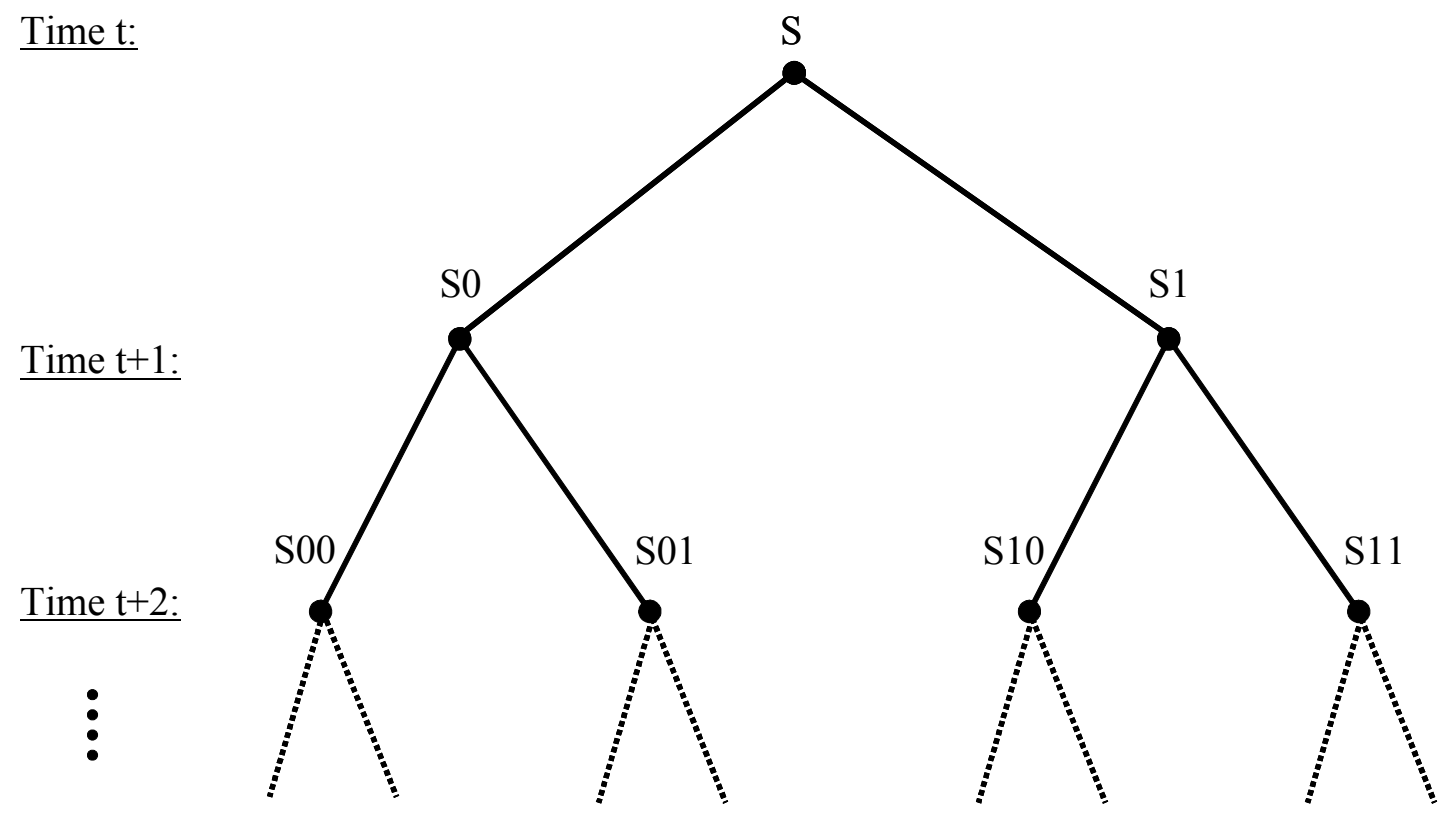

Figure 1: Decision tree for a time $t$ price setter. 


\section{Output}
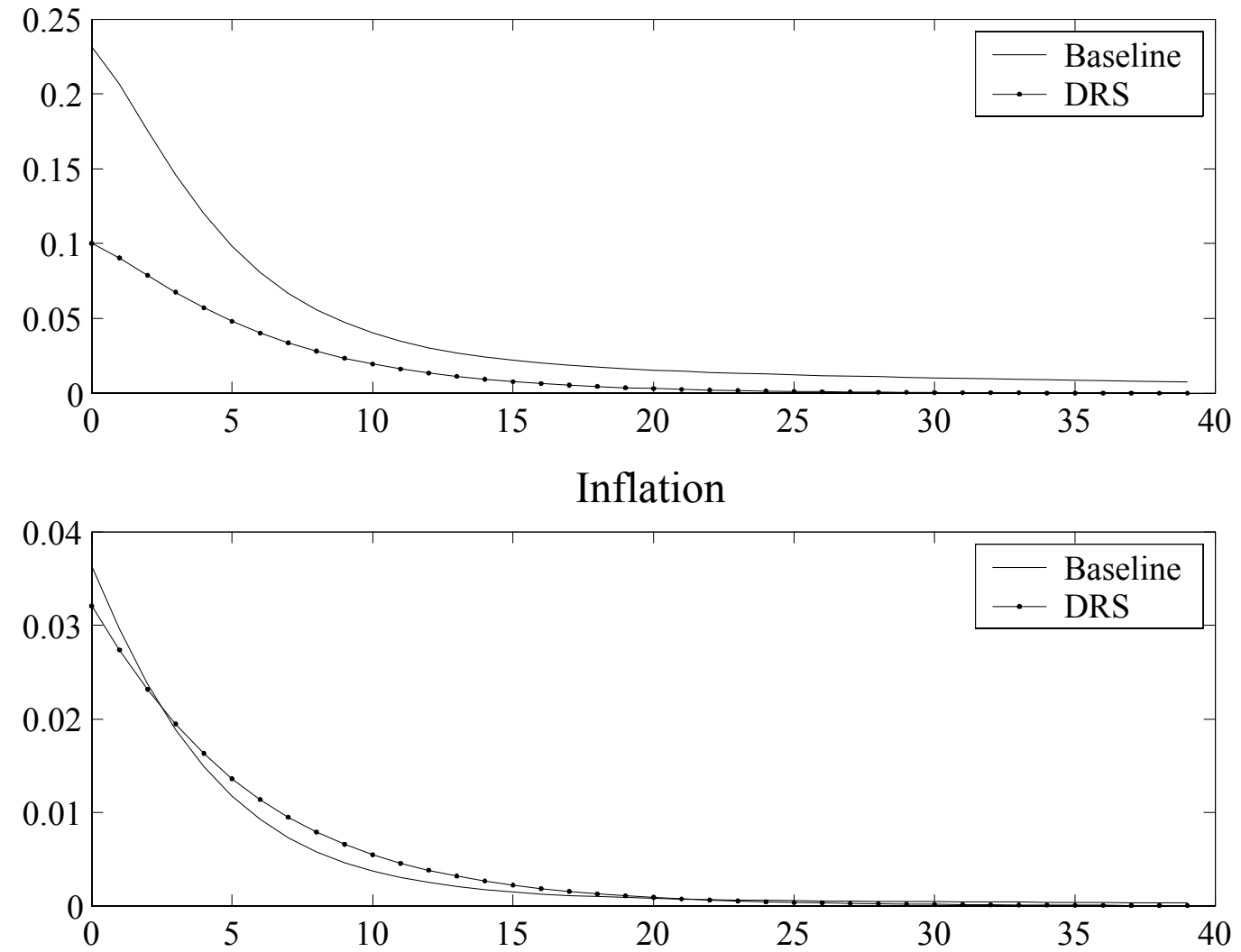

Figure 2: Inflation and output response to a monetary policy shock in the baseline model compared with the DRS specification. 

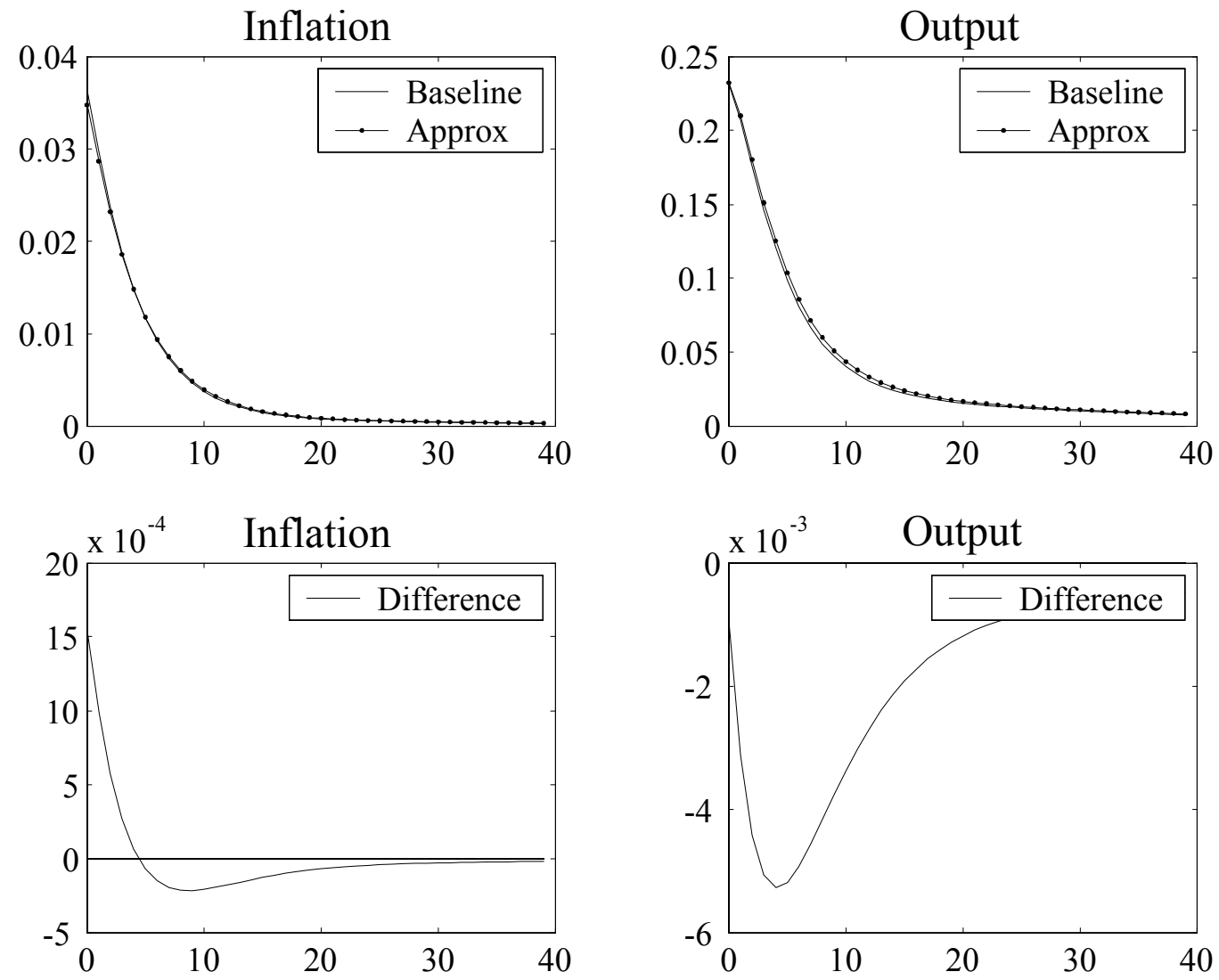

Figure 3: Capital works through the marginal cost. 